\title{
The Level of Internet Addiction Among High School Students at Irbid Public Schools, And Its Relationship with Their Psychosocial Adaptation Problems
}

\author{
Abdullah Al-Shoqran \\ Irbid University College, Al-Balqa' Applied University, P.O. box 1293, Irbid, Jordan
}

\begin{abstract}
This study aims to identify the Internet addiction level among high school students at Irbid public schools and its relationship with their psychosocial adaptation problems. Study population consists of high school students at the public schools of Irbid city for the 2018/2019 school year where a random categorical sample of (337) male and female students was selected. Researcher used two study instruments to collect data: the first relates to Internet addiction and the second relates to the psychological and social problems. Study results found that Internet addiction level among study sample members was high and it showed that most important goals of Internet browsing or surfing among study sample were the electronic games and entertainment, such as movies, sport games, and YouTube, in addition to chatting and social communication. The study indicated that most important negative results related to the Internet use were feeling nervous frequently and the unwillingness to sit down with people and it revealed that problems level of psychological and social adaptation was high. Study found statistically significant differences at level $(\alpha=0.05)$ for Internet addiction due to (gender, browsing hours rate per session, first term average) variables while there weren't any statistically significant differences at level $(\alpha=$ 0.05 ) that may be attributed to the (study branch, grade) variables. Study also found a statistically positive significant relationship between the Internet addiction level among high school students at Irbid public schools and their psychosocial adaptation problems.
\end{abstract}

Keywords: Internet addiction, Irbid public schools, psychological adaptation, psychosocial adaptation, social adaptation

DOI: $10.7176 / \mathrm{JEP} / 10-30-05$

Publication date:October $31^{\text {st }} 2019$

\section{Introduction}

The world today witnesses tremendous developments in all areas and has reflection on people behaviors and dramatically change their way of life and these changes did generally affect all fields of life in different ways where many of it could be positive but the negative effects weren't far from happening. The use of Internet today consider a type of cutting-edge technology which resulted in a tremendous revolution in the human life, developed people's life, and changed their working habits in a way that led to great benefits in their life but wasn't without the occurrence of unwanted and unwelcomed behaviors in the course of bringing these technology to human life details. Internet addiction which has been experienced by many of the young and old individuals has become a challenge and a problem that face different societies due to its negative effects on individuals and societies alike represented in the physical, psychological, intellectual, social, and cultural negative effects, and may even affect the political fields.

A study by Castiglione (2008) related to the abuse and addiction of Internet use among university students at the university and library environment concluded that inappropriate use of Internet could lead to negative educational results of students despite the lack of empirical evidences to prove this phenomenon. Therefore, researcher recommended the need to conduct real international researches to clarify the dimensions of this phenomenon while (Demir \& Kutlu, 2018) emphasized the importance of adolescence as a critical period of human life where the decisions of this group will become very important and determine the rest of their life's destiny and consider an important stage of individuals personal, academicals, and behavioral development but at the opposite it may show dangerous behaviors, such as alcoholism, gangs negative affiliation, and Internet addiction which isn't less dangerous than other problems that affect the life of individuals and societies and it clearly affect the psychological and social development of adolescents in addition to their academic life.

American Psychiatric Association (2014) also explained that an individual's lack of control over the Internet use, the continuous preoccupation, depression, mood change, withdrawal, and the disruption of social, professional, and academic functions may refer to the concept of Internet addiction among individuals, but (Czincz \& Hechanova, 2009) referred to the fears and uncertainties related to Internet addiction, which could intensify due to the rapid growth of different social networks, where the participation in it has become part of the individuals' identity and a form of social acceptance among youngsters. In addition, Al-Khawaja (2014) mentioned that students who show a tendency of Internet addiction have a negative academic performance and they constantly postpone their homework. 
From this standpoint, the excessive use of Internet without controls and follow-up from all parts of society, may lead to psychological and social problems among individuals, and result in significant negative changes in the individual's life and societies, which calls for very serious attention to this topic, and not to ignore it or neglect it.

\section{Study Problem \& Questions}

The spread of computers and mobile phones, and the low prices of Internet subscriptions led to the huge spread of these technologies specifically among the youth group, until it entered into all life activities of those societies' groups, and many of them spend long hours on the Internet for a variety of reasons, where some of it could be justified for various reasons, and some other may be unjustified and have no good reason. This refers to the Internet addiction which become a serious topic that everyone suffer from, both at the individual level, and at the family and society level, and developed into a disturbed topic for most of the world's societies, and its study becomes crucial due to the harmful and dangerous effects of its spreading on all part of the societies, and its association with different and numerous factors that may result in the psychological and social problems among individuals, which requires the study of this topic and analyze its association with the different factors that may affect it directly or indirectly, especially in this category of students who fall between (16-18) years, and have a clear tendency to spend long hours using the Internet for various purposes, and this what have been noticed among the high school students in our society.

From this perspective, the current study came to put emphasis on the Internet addiction level among high school students at Irbid public schools, and its relationship with their psychological and social adaptation problems, and the impact of some variables in this topic, by answering the following main study questions:

1. What is the level of Internet addiction among high school students at Irbid Public Schools?

2. What are the objectives of Internet browsing among high school students at Irbid Public Schools, from their standpoint?

3. What are the negative results of using Internet among high school students at Irbid Public Schools, from their standpoint?

4. What is the level of psychosocial adaptation problems among high school students at Irbid public schools?

5. Are there any statistically significant differences at level $(\alpha=0.05)$ for the Internet addiction among high school students at Irbid public schools that may be attributed to the variables of (study branch, gender, grade, average browsing hours per session, average in the first semester)?

6. What is the relationship between Internet addiction level among high school students at Irbid public schools, and their psychosocial adaptation problems?

\section{Study Objectives}

This study mainly aims to reveal the level of Internet addiction among high school students at Irbid public schools, and its relationship with their psychosocial adaptation problems, and the impact of some variables on Internet addiction, in order to highlight the dimensions of this problem and show its related fields. It also aims to provide indicators about the potential reasons for Internet addiction among teenagers. In addition, study tries to provide indicators about the negative effects of Internet addiction, which may benefit the decision makers to identify the scope of this problem, pursued it, control it, and treat it.

\section{Study Importance}

Study importance stems from the importance of Internet addiction topic and its impact on the society members in general, as well as its impact on high school students as an important group, which goes through a crucial phase of its life. This group falls in adolescence, and attempt to finish high school which determines the course of student's life and the extent of their progress in school. It seek for more attention to the negative effects which can make the student's scientific and educational level move down or even fail for one reason or another, making it important to study the factors that negatively affect student's life, and work to reduce it or prevent it. Therefore, the current study comes in order to shed light on the risk areas and the extent of Internet addiction problem, and its relationship with the social and psychological problems, which help the decision makers at the Ministry of Education and parents to identify the problem extent and its dimensions. The current study also considers as enrichment for the studies that were written in this field and it promote these studies, and push for more attention to this phenomenon and not to ignore it. In addition, the importance of the study represented in detecting the objectives of Internet use among high school students and the negative results of this utilization.

\section{Theoretical Framework}

The use of modern Internet-related technologies have become the backbone of contemporary life., especially with the developments in technology, communication networks, and the Internet, but there is another trend that 
emerges as a result of these technologies which represented in the excessive reliance on these techniques, at unjustified form, and even go beyond the scope of normal use, until it became known as a problem that may similar to the outbreak of infectious diseases. It have seemingly grown deeper in the lives of young people, which made the educational and social institutions agree to launch the term of Internet addiction, and describe it and identify it in different ways. Al-Osaimi (2010) indicated that Internet use is increasing dramatically among individuals, and result in increasing the problems of Internet use. In any case, this overuse of Internet refers to the phrase Internet addiction.

Czincz \& Hechanova (2009: 258) identified Internet addiction as the inability of individuals to control their use of the Internet, which lead to significant difficulties in the areas of mental health of those individuals, and their relationships with other people at school or work. They also have a psychological dependency on the Internet that characterize by increased investment in the activities that they perform on the Internet, therefore they get unpleasant feelings in case they weren't connected to the Internet.

But $\mathrm{KO}$, et al. $(2014,1377)$ defined it as "Loss of control over the Internet use, and it's a major mental health problem that associated with the symptoms of depression and social anxiety among adolescents, around the world".

While Al-Tamimi, et al. $(2007,7)$ identified social media addiction as: "dependency on social media sites for many hours that exceed (21) hours per week, for non-related work issues with the inability of individuals to stop using the Internet, due to their urgent desire to continue using it".

Researcher defines Internet addiction as: "the situation that makes the individuals use the Internet in a compulsive, unhelpful, and useless way, where they become unable to give up following the Internet, and the time period that they use the Internet become notable from the individuals around them, until it affect the different fields of their life.

Some studies have mentioned other expressions on phrases for Internet addiction, such as satisfactory Internet use, compulsive Internet use, computer addiction, and the excessive use of Internet, where these terms refer to the different fields related to the topic of Internet addiction, which are the criteria linked to the definition itself, the date and causes of the problem, and the consequences caused by the addiction problem (Czincz \& Hechanova, 2009).

There are many attractive elements on the Internet, where teenagers find a place to bring out the hidden feelings that they haven't expressed before, and this will be through the friendships on the social networks while they hide their identities so they won't be known, and receive many services for free. In addition, the multiplicity and numerousness of nationalities on the Internet are also causes for its attractions. The intensive and uncontrolled use of Internet generate many physical, psychological, social, cognitive, and developmental problems, and also led to insomnia and decline of health and working life, along with the psychological problems and the impact on mental health and thinking capabilities, which can be called reshaping the lives of teenagers and children (Taş, 2017).

Surveys on Internet addiction (2001), which included a sample of 8,666 Internet users from Germany, Austria, and Switzerland found there are five criteria applicable to the Internet addicts, which are: the first criterion is loss of control over Internet use, the second is increase the endurance of Internet use significantly, the third is appearance of isolation, nervousness, and intensity of temper symptoms, the fourth is negative social effects, such as isolation and loss of social communication, and fifth criterion is the negative effects on work or school. It showed from this field survey that younger individuals are more vulnerable to Internet addiction than older individuals (Kenneth \& Woog, 2004).

Abdul Razaq (2013) emphasized that youth group consider the most common users of computers and mobile devices which are constantly connected to the Internet through the various websites, such as social network sites until it affected their entire life and worked on turning it toward different directions especially since it got the characteristics that made it one of the most popular and widely used methods, such as interactivity, diversity, integration, instantaneous, and the freedom of expression without restrictions. These characteristics made the Internet a method of great influence on all age groups and there is no suspicion that youngsters are at the forefront of those groups.

Varma, et all (2018) indicated that Internet addiction and its different level from the normal use of Internet shows through monitoring the behavioral changes that occur in individuals in case of blocking the permission to access a desired site or the Internet completely, where the normal user's behavior seems normal and nonreflective, as they use the Internet for their normal daily needs, but the behavior of Internet addicts isn't where they show a clear refusal to prevent their access to the Internet and don't behave normally. Those users usually spend a lot of time on the Internet which affect the course of their life and their relationships with family, friends, work, and school. However, there are lack of experiences and researches to verify these things, especially indepth researches into these phenomena.

Arpaci et al. (2017) added some psychological problems that arise and result from Internet addiction but those problems may vary from one society to another which follows the surrounding environment factors of 
individuals and the circumstances that are connected to each case of Internet addiction. Researchers also made a connection between the Internet and some of the psychological problems, such as isolation.

Therefore, the Internet addiction is associated with psychological illness problems and symptoms which go beyond the stereotype of ordinary computer users and these symptoms may be in parallel with addiction in its traditional sense by repeating the behavior without the ability to resist it or stop it. The limitations of social, educational, and practical fields among Internet addicts and the negative effects of psychological state that they have after using the Internet and enjoying it in the different ways indicate that future researches related to Internet addiction should emphasize and examine its association with the various fields (Hajj, 2017).

In regard to the psychological adaptation, Sofian $(2004,153)$ defined it as: "the individual's satisfaction of psychological needs, self recognition, enjoyment of life that is free of tensions, conflicts, and mental disorders, enjoyment of intimate social relationship and the participation in social activities, and the recognition of habits, traditions, and values of the society". Sofian $(2004,155)$ also defined the social adaptation as: "individual's enjoyment of the intimate social relationships that characterized by respect, appreciation, and mutual generosity which satisfy their social needs, in addition to the participation in social activities and the acceptance of customs, traditions, values, ideas, laws, and rules of the society".

While Al-Said $(2017,25)$ defined the psychological and social adaptation as: "the basis of all types of social adaptation that depend on the interaction between the individuals and the surrounding environment, and its the ability to establish good relationships with the family members and friends at work on the basis of tenderness, fondness, appreciation, and mutual respect and the acceptance of themselves and other people around them".

Researcher of the current study defined the problems of psychological and social adaptation as: the inability of individuals to psychologically adapt to the pressures and problems that they personally face, their inability to incorporate with the surrounding environment and the lack to establish good relationships with people, such as family members, friends, colleagues, teachers, and society members, and also the occurrence of psychological and social disorders that affect the life of individuals and change the structures of their personalities and thoughts.

Musa (2010) mentioned the aspects of psychological adaptation where the first aspect is the emotional aspect, which show anxiety, disorder, mood inconstancy, tendency to withdraw from the situations that require confrontation, and anger and confusion due to being followed by others while the second is the cognitive aspect which appear through wander, failure to focus, failure to express ideas, and the slowness in knowledge absorption. The third is the values aspect which is associated with the justification of religious intolerance, questioning some of the religious principles, the complement of others without being convince, and the waste of time without investing in it, and finally the fourth is the psychological aspect which associated with selfsatisfaction and shows through the relationship of individual with others and the positive or negative social behavior. Therefore, these fields are very significant because it illustrate the degree of adaptation that individuals achieve between themselves and their societies in general.

In regard to the relationship between Internet addiction and psychosocial adaptation, (Demir \& Kutlu, 2018) pointed out that behavioral addictions among adolescents, like Internet addiction influence the behaviors' factors, such as academic procrastination, academic motivation, attachment to school, and none performance of duties. As a result, achievement of academic goals among Internet addicts are difficult and far-fetched because they are busy with the Internet for long periods of time which make the academic motivations negative for them, therefore Internet addiction clearly reduce the positive academic motivations of adolescents.

While Heron \& Shapira (2003) provided suggestions for the treatment of Internet addiction which represented in psychotherapy based on the study of psychological factors that drive an individual to use the Internet and work to reduce it or treat it, as well as the behavioral treatment based on the study of Internet addicts' different behaviors and the attempt to influence it by directing the behaviors toward directions that push them away from the unjustified Internet use and rebuild the previous routine activities that individuals were performing before getting attached to the Internet use. The use of modern technology also adjust the session's duration for Internet addicts by setting short and fast-achieving goals that can be achieved through the short session periods of Internet and through family help to the addicted individual on the Internet to get rid of this behavior. Rebuilding family relationships between family, Internet addict, and friendships will help to get rid of time waste on the Internet and help individuals to reduce the size of this problem.

By reviewing the theoretical literature the importance of Internet topic is obvious, especially through its connection with the adolescent group of school students and the impact it may cause in their psychological and social adaptation fields. This makes it important to conduct the various and continuous studies about the topic of Internet addiction to identify the ongoing developments in this field, and work to solve the problems that may result from this unjustified Internet use which can destroy the psychosocial situation of many individuals, especially the adolescents who may be more motivated toward Internet addiction than other age groups.

\section{Previous Studies}

There are several studies that addressed the Internet addiction and its relationship with different topics and 
variables. A review of several studies that were conducted in different areas according to their chronological development, as follow:

Al-Osaimi study (2010) aimed to detect the Internet addiction and its relationship with the psychosocial adaptation among high school students in Riyadh. Study sample consist of (350) students and the researcher used two questionnaires: the first one used to measure the Internet addiction, and the second used to measure the psychological adaptation level. Study results found a negative relationship between the Internet addiction level and the psychosocial adaptation level and showed statistically significant differences between the arithmetic means of addicted students on the Internet and non-addicted students, at the psychosocial adaptation scale in favor of non-addicted Internet students.

While the Study of Al-Tarawneh \& Al-Fanikh (2012) aimed to identify the relationship between Internet use and the academic achievement, social adaptation, communication skills, and depression among Al-Qassim University students. Study sample consists of (595) male and female students from Al-Qassim University and the researcher used the cumulative averages, the Beak list for depression, the social adaptation, and the communication skills scales. Study results revealed that social adaptation level was moderate among the Internet users and that depression level was high among the students with high Internet use, while their communication skills were low and that depression level was low among the students with moderate Internet use. Study found statistically significant differences in favor of those with moderate use of Internet in the areas of academic achievement and social adaptation, as well as the existence of statistically significant differences in favor of males. It also found that depression has a statistically significant impact in favor of those with high Internet use and for females.

But the study of Li, et. all (2014) aimed to examine the circulation level of Internet addiction among a representative sample of the primary and middle schools' students across China and the impact of different Internet uses on the circulation level. Data were taken from a national study that was conducted on this student's sample and researcher used the Young Diagnostic Criteria (YDQ). Results showed that overall Internet addiction rate among the study sample was $(6.3 \%)$ but it was $(11.7 \%)$ among the study sample members who use the Internet where the Internet addiction among males amounted to $(14.8 \%)$ which is higher than the female rate of $(7.0 \%)$. The student's addiction rate at primary school amounted to $(11.5 \%)$, which is close to the addiction rate of middle school students and found a relationship between the increase in time spent on the Internet and the increase in Internet addiction level. Internet addiction rate was higher among teenagers who browse the Internet at the café and at the Internet gaming areas.

The study of Al-Khawaja (2014) aimed to determine the nature of relationship between Internet addiction and the psychological adaptation among students at Sultan Qaboos University. Study sample includes (290) male and female students where the researcher used two instruments to measure the degree of Internet addiction and the degree of psychological adaptation. Study results indicate the existance of reverse correlation between Internet addiction and the psychological adaptation and found that psychological adaptation degree was lower among the individuals who were addicted to the Internet. Statistically males were more addicted to the Internet than females.

While the study of Azher, et. al. (2014) aimed to identify the relationship between Internet addiction and the anxiety level among Sargodha University students in Pakistan. Study sample includes (300) male and female students and researchers used one instrument to measure the Internet addiction and another instrument to measure the anxiety level. Study results revealed that Internet use spread more among male students than females and showed a notable positive relationship between the level of Internet addiction and the anxiety level of students in general.

İlhan, et. al. (2016) conducted a study that aimed to identify the students' attitudes toward the Internet and its relationship with Internet addiction among students of age group (13-18) years and the impact of some variables on students' attitudes. The researchers used a special scale to identify students' attitudes towards the Internet and another to measure Internet addiction which were prepared by other researchers. Study sample consists of (286) male and female students from high schools in Kahraman Maras. The results revealed that students' attitudes toward the Internet came with an arithmetic mean of (3.66) which is compatible with the score "agree" and showed that the degree of students' level on the Internet came with an arithmetic mean of (2.11). Results showed that students' responses to Internet addiction items were at the level of potential tendency toward Internet addiction where the correlation analysis revealed a positive relationship between the student's attitudes toward the Internet and their Internet addiction. The regression analysis showed that Internet addiction can be predicted through students' attitudes toward the Internet.

But the study of Iyitoğlu \& Çeliköz (2017) aimed to explore the relationship between Internet addiction and the academic performance of some educational courses among high school students in Turkey. Study sample consists of (217) male and female students and the researchers relied on a instrument that was prepared in advance by other researchers to measure the degree of Internet addiction, and student averages were adopted in some subjects. Results indicate the absence of statistical differences in Internet addiction that could be attributed 
to the sex variable and found a positive relationship between Internet addiction and the academic performance in the English course, but found a negative correlation at the overall course rate and didn't show any relationship between the achievement in History, Mathematics, and the Internet addiction.

Al-Naimi (2017) conducted a study that aimed to reveal the relationship between Internet addiction and the psychosocial adaptation for the College of Physical Education and Sports Sciences students at Diyala University in Iraq. Study sample consists of (274) male and female students and the researcher used two scales: one to measure the Internet addiction, and the other to measure the psychosocial adaptation. Study results revealed that Internet addicts rate among the study sample members amounted to $(41 \%)$ which is higher than the $(25 \%)$ of non-Internet addicts.

Finally, Ibili (2017) conducted a study that aimed to identify the Internet addiction level and its relationship with the problem solving skills and the recognition of self-professionalism among the students candidate to work at the teaching profession in Turkey. Study sample includes (268) male and female students and to collect data for the study the researcher use the instruments of other researchers and modified them to align with this study. Study results showed a moderate negative relationship between the addiction level, problem-solving skill, and the self-professionalism while there was a higher positive correlation between the self-professionalism and problem-solving skills and showed that Internet fuse for entertainment purposes is statistically significant at problem-solving skills but the study sample members who used the Internet for research purposes showed a higher level of problem-solving capabilities and lower levels of Internet addiction.

Comments on the Previous Studies:

It showed by reviewing the previous studies there are studies that addressed the relationship of Internet addiction with the psychosocial adaptation and those studies showed a variation in that relationship. It showed that non-addicted students to the Internet are more psychologically and socially compatible while other studies have linked Internet use with the academic achievement and depression and the relationship between them, and some of those dealt with the gender variable. Some studies addressed the impact of different Internet uses on the Internet addiction and other studies addressed the relationship between Internet addiction and the anxiety level among students. Several studies tried to reveal the relationship between students' attitudes toward the Internet and its relationship with the Internet addiction but one study sought to reveal the relationship of Internet with the skill of problems solving and the self-professionalism.

It also showed from reviewing the previous studies that they were in areas other than Jordan while the current study focus on Internet addiction and its relationship with the psychological and social adaptation in Jordan, and particularly in Irbid area.

The current study consider an extension of the studies which reveal the developments that can occur within individuals during Internet addiction and may show the change level of students over time as a result of Internet addiction which must be followed continuously from time to time, in order to control it and prevent the problems resulting from it from being Intensified especially with the development of Internet field and the development of modern devices. Current study differs from previous studies in its attempt to detect the psychological and social problems that result from Internet addiction and also tried to detect the objectives of Internet browsing, and highlight the negative results of Internet use among study sample.

\section{Study Methodology \& Procedures}

The descriptive survey method was used in the current study and the two study instruments were used to collect data from the study sample in order to identify the Internet addiction level among high school students at Irbid public schools, and used the correlation study to identify the relationship between Internet addiction and the psychosocial adaptation problems among the study sample.

\subsection{Study Terms:}

Here's a presentation of the procedural terms in the study:

Matar et al. $(2009,301)$ defined Internet addiction as: "A combination of continuous psychological dependence symptoms to deal with the Internet for long periods with the intention to enter into a state of excitement without an academic need and the emergence of many criteria accompanied by the psychosocial withdrawal symptoms, such as loss of social support and feelings of depressive symptoms". Internet addiction level procedurally is defined as the response rate of study sample members on the study instrument which related to the Internet addiction.

Al-Hattab $(2015,307)$ identified the psychosocial adaptation as: "The individual's attempt to overcome the obstacles that stand in the way of their needs or their motives in order to satisfy their personal and social needs". Procedurally, the Psychosocial adaptation problems are defined as: the response rate of study sample members on the study instrument paragraphs which related to the problems of psychosocial adaptation. 


\subsection{Study Limitations:}

Study results in general are determined by a set of determinants, as follow:

Time Limits: the study procedures and results are limited to the $(2018 / 2019)$ school year which is the period that study was conducted.

Spatial Determinants: the study procedures were conducted in Irbid city and its schools, where the study sample is limited to the public high schools in this city only.

Objective Determinants: study topic is limited to the Internet addiction level, and its relationship with the psychosocial adaptation problems.

Human Determinants: the study sample was selected from high school students at the public schools in Irbid city only.

\subsection{Study Population \& Sample:}

The study population included all the $(14,940)$ male and female high school students at Irbid public schools during the second quarter of (2018/2019) school year, $(7,223)$ of those are male students and $(7,717)$ are female students. A random class sample of (337) male and female students was selected and table (1) shows the distribution of study sample members based on study variables.

Table (1) Frequencies and percentages of study sample members' distribution according to the study variables

\begin{tabular}{llll} 
Variables & Classes & Frequencies & $100 \%$ \\
\hline \multirow{3}{*}{ Study Branch } & Scientific & 92 & 27.3 \\
& Literary & 154 & 45.7 \\
& Other Branches & 91 & 27.0 \\
\hline \multirow{2}{*}{ Gender } & Male & 179 & 53.1 \\
& Female & 158 & 46.9 \\
\hline \multirow{2}{*}{ Grade } & First High school & 169 & 50.1 \\
& Second High school & 168 & 49.9 \\
\hline \multirow{2}{*}{ Average browsing hours per } & Less than 2 hrs & 129 & 38.3 \\
session & Between (2-5) hrs & 120 & 35.6 \\
& Greater than 5 hrs & 88 & 26.1 \\
\hline \multirow{2}{*}{ First Term Average } & Between (80-100) & 143 & 42.4 \\
& Between (60-79) & 144 & 42.7 \\
\hline & Less than 60 & 50 & 14.8 \\
\hline
\end{tabular}

It shows through table (1) that number of first high school students $(50.1 \%)$ was close to the number of second high school students $(49.9 \%)$, the male's proportion of $(53.1 \%)$ and females of $(46.9 \%)$ was close to some extent and but there was a variation in the number of students due to other variables.

\subsection{Study Variables:}

The study seeks to reveal Internet addiction level among high school students at Irbid public schools and its relationship with their psychological and social adaptation problems. Study addressed the impact of the following dependent and independent variables on this topic:

7.4.1 Independent variables, and include the following:

- Study Branch: it include three levels (scientific, literary, other branches)

- Gender: it include two levels (male, female)

- Grade: it include two levels (first high school, second high school)

- Average browsing hours per session: it include three levels (less than 2 hrs, between (2-5), greater than 5)

- First Term Average: it include three levels (between (80-100), between (60-79), less than 60)

7.4.2 Dependent variables, and include the following:

- Internet addiction level among high school students at Irbid public schools.

- Psychological and social adaptation problems among high school students at Irbid public schools.

\subsection{Study Instruments:}

After reviewing the theoretical literature and previous studies related to the study topic researcher relied on a group of studies, such as Müller, et, al. (2014), Kesici \& Tunç (2018), and Karimzadeh (2015) to prepare the Internet addiction instrument and depended on the study of Abu Sukran (2009) to create the psychological adaptation instrument. The two study instruments were created in their final form from (44) items and were divided into three parts, the first part include instructions and personal information, the second part include Internet addiction instrument and contained three fields which are Internet addiction and consists of (10) items, 
the second field is Internet browsing goals and consists of (9) items and the third field is negative results of using the Internet and consists of (9) items, while the third part include the instrument of psychological and social adaptation problems and contains two fields, the first is psychological adaptation problems and consists of (7) items, and the second field is social adaptation problems and consists of (8) items.

\subsection{Study Instruments Validity:}

In order to virtually verify the validity of the two study instruments, it were presented in their initial form which included (48) items on (9) arbitrators from the specialized faculty members in the Jordanian universities in order to verify the validity of study instruments' items in terms of language formulation, linguistic errors, and clarity and achieve the intended goals, and also to identify the items that need to be modified, deleted, or added. After collecting the arbitrators' opinions and modifying the instruments based on their observations and suggestions (5) items were deleted, (1) item was added, and (4) items were modified to make the two instruments in their final form consist of (44) items. The proportion of items that weren't change reached $(90 \%)$ which indicate the validity of items in the two instruments and representing it to its fields and the goal it were designed for.

The Five Likert scale was adopted to correct the two study instruments, by giving each item in it one degree out of five (strongly agree, agree, neutral, disagree, strongly disagree), which digitally represent the numbers $(5$, $4,3,2,1)$ respectively and the following scale was adopted for the purposes of results analysis:

$(1.00-2.33)$ as low

$(2.34-3.67)$ as medium

(3.68-5.00) as high

The scale was calculated by using the following equation:

The upper limit of scale (5) - the lowest scale (1)/number of categories required (3)

$(5-1) / 3=1.33$

Therefore, (1.33) will be added to the end of each category.

\subsection{Study Instruments Reliability:}

Correlation coefficient of the two instruments and the instrument as a whole were calculated to verify the reliability of study instruments and its fields and the Cronbach Alpha coefficient revealed the following results, as shown in table (2) and (3) below:

7.7.1 Internet addiction instrument:

Table (2): Alpha Cronbach Coefficient for the Internet Addiction instrument for each field of the instrument and for the instrument as a whole

\begin{tabular}{lll} 
Field & Repetition & Alpha \\
\hline 1 & 0.76 & 0.89 \\
\hline 2 & 0.81 & 0.86 \\
\hline 3 & 0.77 & 0.84 \\
\hline Instrument as a whole & 0.83 & 0.91
\end{tabular}

7.7.2 Psychosocial adaptation problems instrument:

Table (3): Alpha Cronbach Coefficient for the psychosocial adaptation problems instrument for each field of the instrument and for the instrument as a whole

\begin{tabular}{lll} 
Field & Repetition & Alpha \\
\hline 1 & 0.79 & 0.85 \\
\hline 2 & 0.84 & 0.90 \\
\hline Instrument as a whole & 0.86 & 0.93
\end{tabular}

It shows from table (2) that Cronbach Alpha Coefficient for the fields of Internet addiction instrument ranged between (0.84-0.89) and the Cronbach Alpha coefficient for instrument as a whole was (0.91). It also shows from table (3) that Cronbach Alpha Coefficient for the two fields of psychosocial adaptation problems were $(0.85 \& 0.90)$ and the Cronbach Alpha Coefficient for instrument as a whole was $(0.93)$ and these ratios considered acceptable to indicate the reliability of study instruments as a whole.

\section{Statistical Analysis, Study Results \& Discussions}

8.1 Statistical Analysis:

The SPSS package was used to enter the data that were collected from study sample and the following statistical analysis were used: H6F5Q45 for the study instrument as a whole and used the fifth variation analysis to test the impact of study branch, gender, grade, and the first term average on the Internet addiction level among high school students at Irbid public schools. The Dimensional Post Hoc Multiple Comparisons were implemented by using the Scheffe Method to test the multi-level variables which showed statistically significant differences to identify the Internet addiction significant level among high school students at Irbid public schools. Finally, the 
Pearson's Correlation Coefficient was used to reveal the relationship between the Internet addiction level among high school students at Irbid Public Schools and their psychosocial adaptation problems.

\subsection{Study Results \& Discussions:}

The study tried to detect the Internet addiction level among high school students at Irbid public schools and its relationship with the psychosocial adaptation problems. Here is a presentation of study results according to its questions:

First Question: What is the level of Internet addiction among high school students at Irbid Public Schools?

To answer this question the arithmetic means and standard deviations were calculated for the level of Internet addiction among high school students at Irbid public schools, as shown in table (4) below:

Table (4) Arithmetic means \& standard deviations of the Internet addiction level among high school students at Irbid Public Schools in a descending order according to means

\begin{tabular}{llllll} 
Rank & Number & Item & Mean & STDEV & Level \\
\hline 1 & 10 & Areas that I can't use the Internet in it are boring & 4.39 & 0.89 & High \\
\hline 2 & 1 & $\begin{array}{l}\text { I don't recognize what's happening around me whenever I am } \\
\text { browsing the Internet }\end{array}$ & 4.28 & 0.95 & High \\
\hline 3 & 8 & I surf the Internet while I'm with my friends & 3.62 & 1.62 & Medium \\
\hline 4 & 5 & I can express myself while I am browsing the social media & 3.57 & 1.50 & Medium \\
\hline 5 & 4 & I strongly feel the need to browse social media & 3.49 & 1.34 & Medium \\
\hline 6 & 6 & $\begin{array}{l}\text { Whenever I am eating, I browse the Internet through a method } \\
\text { of communication, such as (mobile phones, tablets, desktops) }\end{array}$ & 3.48 & 1.38 & Medium \\
\hline 7 & 7 & I surf the Internet while I'm with my family & 3.47 & 1.59 & Medium \\
\hline 8 & 3 & $\begin{array}{l}\text { I get upset whenever someone visit me (relative, friend) } \\
\text { because they stop me from using Internet }\end{array}$ & 3.46 & 1.58 & Medium \\
\hline 9 & 2 & $\begin{array}{l}\text { I feel uncomfortable (bored) whenever I don't spend much time } \\
\text { on the Internet }\end{array}$ & 3.39 & 1.46 & Medium \\
\hline 9 & 9 & $\begin{array}{l}\text { I haven't manage to reduce the number of Internet browsing } \\
\text { times }\end{array}$ & 2.54 & 0.98 & Medium \\
\hline 11 & 11 & $\begin{array}{l}\text { Despite my body pain and overtiredness as a result of browsing } \\
\text { the Internet, I continue to browse it in the same session }\end{array}$ & 2.22 & 1.13 & Low \\
\hline Internet Addiction & 3.45 & 0.98 & Medium
\end{tabular}

Table (4) shows that arithmetic means were between (2.22-4.39), where item (10): "Areas that I can't use the Internet in it are boring" came at first place with a mean of (4.39) and a high level while item (11): "Despite my body pain and overtiredness as a result of browsing the Internet, I continue to browse it in the same session" came at the last place, with a mean of (2.22) and a low level. The arithmetic mean of Internet addiction as a whole was (3.45) at medium level.

Previous results indicate a high estimate of Internet addiction by study sample members which may consider unhealthy indicator of Internet use among the study sample members and this may be attributed to several factors, such as the widespread of Internet use in the Jordanian society, the definite reliance on Internet at the various fields, the low cost of subscriptions to the Internet, the spread of mobile phone devices, the low price of phones, and the apparent development of communications for the various uses through the Internet. In addition, students tend to copy family members, relatives, classmates, and friends in the possession of advanced mobile devices which are connected to the Internet.

All these factors have caused the Internet to spread among the public primarily through using the mobile phones and other methods where middle age students between (14-18) years nowadays carry the mobile devices that are directly connected to the Internet which make the possibility of using it and the freedom of restricting its used period left to this age group without accountability or control due to last of parents control over these social media for different reasons among children and adults, such as studying, contacting friends, doing homework through the Internet which make the control of parents to their children's Internet use very complicated.

Second Question: What are the objectives of Internet browsing among high school students at Irbid Public Schools from their standpoint?

To answer the second question the arithmetic means and standard deviations were calculated for the Internet browsing objectives among high school students at Irbid public schools, as shown in table (5) below: 
Table (5) Arithmetic means \& standard deviations for the Internet browsing objectives among high school students at Irbid Public Schools in a descending order according to means

Rank Number Item

\begin{tabular}{llllll} 
Rank & Number & Item & Mean & STDEV & Level \\
\hline 1 & 15 & $\begin{array}{l}\text { Electronic games and entertainment (movies, sports games, } \\
\text { YouTube) }\end{array}$ & 4.32 & 1.15 & High \\
\hline 2 & 13 & Chatting and social media & 3.97 & 1.38 & High \\
\hline 3 & 12 & Electronic Mail (E-mail) & 3.78 & 1.46 & High \\
\hline 4 & 20 & Doing homework & 3.33 & 1.37 & Medium \\
\hline 5 & 18 & Educational websites & 3.29 & 1.52 & Medium \\
\hline 6 & 17 & News websites & 2.97 & 1.45 & Medium \\
\hline 7 & 14 & Purchasing through the Internet & 2.95 & 1.53 & Medium \\
\hline 8 & 16 & Search platforms for scientific information & 2.84 & 1.70 & Medium \\
\hline 9 & 19 & Conducting scientific researches & 2.73 & 1.28 & Medium \\
\hline Internet Browsing Objectives & 3.35 & 0.98 & Medium
\end{tabular}

Table (5) shows that arithmetic means were between (2.73-4.32) where item (15): "Electronic games and entertainment (movies, sports games, YouTube)" came at first place with a mean of (4.32) at high level while item (13): "Chatting and social media" came in second place with a mean of (3.97) at high level but item (19): "Conducting scientific researches" came at last place with a mean of (2.73) at medium level and the arithmetic mean of Internet browsing objectives as a whole was (3.35) at medium level.

These results may indicate that Internet use by the study sample members are used mostly for non purposeful fields, such as entertainment and electronic games. It has been also used to chat via the different social networks which have become a method that adults and young people are addicted to and can't give up very easily. This create an obvious risk factors for high school students which consider an important stage of their life as time is an important factor to make this stage in their favor but the loss of time through the excessive use of Internet will eventually lead to unwelcomed and unfavorable problems for this age group. It seems that Internet use for students at this stage isn't intended for the important and useful purposes where it appeared through their responses to the questions on the study instrument that Internet use to conduct scientific researches and search for information weren't as important for them as electronic games and entertainment.

Third Question: What are the negative results of using Internet among high school students at Irbid Public Schools from their standpoint?

To answer the third question the arithmetic means and standard deviations were calculated for the Internet browsing objectives among high school students at Irbid public schools, as shown in table (6) below:

Table (6) Arithmetic means \& standard deviations for the negative results of using Internet among high school students at Irbid Public Schools in a descending order according to means

\begin{tabular}{llllll} 
Rank & Number & Item & Mean & STDEV & Level \\
\hline 1 & 29 & I frequently become nervous & 3.93 & 1.33 & High \\
\hline 1 & 27 & I don't like sitting down with people & 3.93 & 1.33 & High \\
\hline 3 & 23 & I spend a lot of money on internet access & 3.78 & 1.43 & High \\
\hline 4 & 22 & The occurrence of problems in my study & 3.77 & 1.41 & High \\
\hline 5 & 24 & The occurrence of problems in my vision & 3.69 & 1.21 & High \\
\hline 6 & 28 & I feel isolated from those people around me & 3.53 & 1.39 & Medium \\
\hline 7 & 21 & The occurrence of different problems with my family & 3.03 & 1.47 & Medium \\
\hline 8 & 26 & The occurrence of different problems with my body & 2.93 & 1.44 & Medium \\
\hline 9 & 25 & I neglect and avoid my friends & 2.81 & 1.49 & Medium \\
\hline Negative Results of Using Internet & 3.49 & 1.03 & Medium
\end{tabular}

Table (6) shows that arithmetic means were between (2.81-3.93) where items (27 \& 29): "I frequently become nervous", "I don't like sitting down with people" came at first place, with a mean of (3.93) at high level while item (25): "I neglect and avoid my friends" came at the last place with a mean of (2.81) at medium level and the arithmetic mean of negative results of using Internet as a whole was (3.49) at medium level.

The responses of study sample members reveal some negative results for using the Internet, such as feeling nervous, disliking to sit with people, and spending a lot of money on Internet connection. This may be attributed to the attachment of a large number of study sample members to the Internet and spending long time browsing its WebPages for reasons like electronic games, entertainment, and social networking which make them unable to control their behaviors in browsing the Internet but on the contrary they tend to spend a long time browsing the Internet without feeling tired, overstrain, and in a semi-involuntary way which may result in future problems that they can't predict or control due to reaching a state of addiction and being unable to get rid of Internet serving in order to satisfy their various unjustified social or behavior needs and objectives.

Forth Question: What is the level of psychosocial adaptation problems among high school students at Irbid 
public schools?

To answer the fourth question the arithmetic means and standard deviations were calculated for the psychosocial adaptation problems among high school students at Irbid public schools, as shown in table (7) below:

Table (7) Arithmetic means \& standard deviations for the psychosocial adaptation problems among high school students at Irbid Public Schools in a descending order according to means

\begin{tabular}{llllll}
\multicolumn{1}{c}{ Rank } & Number & Item & Mean & STDEV & Level \\
\hline 1 & 1 & Psychological adaptation problems & 3.83 & 0.88 & High \\
\hline 2 & 2 & Social adaptation problems & 3.56 & 1.00 & Medium \\
\hline \multicolumn{2}{l}{ Psychosocial Adaptation } & Problems & 3.69 & 0.90 & High
\end{tabular}

Table (7) shows that arithmetic means were between (3.56-3.83) where items (1): "Psychological adaptation problems" came at first place with a mean of (3.83) at high level while item (2): "Social adaptation problems" came at the last place with a mean of (3.56) at medium level, and the arithmetic mean of psychosocial adaptation problems as a whole was (3.69) at high level.

The arithmetic means and standard deviations for the estimates of study sample members were calculated on the items of each field separately, as follow:

First Field: Psychological adaptation problems

Table (8) Arithmetic means \& standard deviations for the field of psychological adaptation problems in a descending order according to means

\begin{tabular}{llllll} 
Rank & Number & Item & Mean & STDEV & Level \\
\hline 1 & 34 & I can't give up using social media & 4.64 & 0.77 & High \\
\hline 2 & 30 & $\begin{array}{l}\text { I have many friends on social media that I have } \\
\text { never met them in person before }\end{array}$ & 4.56 & 0.82 & High \\
\hline 3 & 33 & I feel that time is short to do my daily duties & 3.95 & 1.43 & High \\
\hline 4 & 32 & I feel happy whenever I'm alone & 3.78 & 1.27 & High \\
\hline 5 & 31 & I'm constantly feeling worried & 3.57 & 1.45 & Medium \\
\hline 6 & 36 & I sleep irregularly at night & 3.37 & 1.47 & Medium \\
\hline 7 & 35 & It bothers me having headaches constantly & 2.96 & 1.53 & Medium \\
\hline \multicolumn{2}{l}{ Psychological Adaptation Problems } & 3.83 & 0.88 & High
\end{tabular}

Table (8) shows that arithmetic means were between (2.96-4.64) where items (34): "I can't give up using social media" came at first place with a mean of (4.64) at very high level while item (35): "It bothers me having headaches constantly" came at the last place with a mean of (2.96) at medium level, and the arithmetic mean of psychological adaptation problems as a whole was (3.83) at high level.

Second Field: Social adaptation problems

Table (9) Means \& standard deviations for the field of social adaptation problems in a descending order according to means

\begin{tabular}{llllll} 
Rank & Number & Item & Mean & STDEV & Level \\
\hline 1 & 39 & $\begin{array}{l}\text { My family doesn't appreciate how much I need the } \\
\text { Internet to use it on social media }\end{array}$ & 4.13 & 1.28 & High \\
\hline 2 & 42 & $\begin{array}{l}\text { I don't participate in family's related decisions } \\
\text { Social media }\end{array}$ & 4.01 & 1.34 & High \\
\hline 3 & 41 & $\begin{array}{l}\text { M family makes fun of me whenever I use the } \\
\text { I feel upset whenever I'm at school }\end{array}$ & 3.88 & 1.45 & High \\
\hline 4 & 43 & I feel estranged while I'm at home & 3.74 & 1.48 & High \\
\hline 5 & 44 & I have good relationships with my colleagues & 3.09 & 1.33 & Medium \\
\hline 6 & 38 & I communicate well with my neighbors & 2.94 & 1.30 & Medium \\
\hline 7 & 40 & $\begin{array}{l}\text { I accept the criticism of other people whenever I am } \\
\text { busy with social media }\end{array}$ & 2.82 & 1.44 & Medium \\
\hline 8 & 37 & & 3.56 & 1.00 & Medium
\end{tabular}

Table (9) shows that arithmetic means were between (2.82-4.13) where items (39): "My family doesn't appreciate how much I need the Internet to use it on social media" came at first place with a mean of (4.13) at high level while item (37): "I accept the criticism of other people whenever I am busy with social media" came at the last place with a mean of (2.82) at medium level, and the arithmetic mean of social adaptation problems as a whole was (3.56) at medium level.

These results may be attributed to the different changes that occur among individuals at this age, such as puberty, adolescence, change of interests, change of thinking method, tendency to isolation and individuality, feeling the physical changes that embarrass these age groups, different view about the nature of friends, and the different relationships with others which affect the psychological stability of individuals, and even their 
relationships with others in the surrounding area of society. The excessive reliance on the Internet increases the isolation of individuals and makes them more withdrawn which may create psychological gaps that make individuals feel disoriented and psychologically unstable. As a result, they may develop physical problems and diseases, such as fatness, back and neck pain, vision problems where all of these have negative psychological effects that may deteriorate and become challenging problems that are difficult to solve, and they may become unable to cope with their surroundings area properly. Therefore, the responses of study sample members on the instrument's items of psychological and social adaptation problems were generally high where the problems of psychological adaptation were higher than the problems of social adaptation.

Fifth Question: Are there any statistically significant differences at level $(\alpha=0.05)$ for the Internet addiction among high school students at Irbid public schools that may be attributed to the variables of (study branch, gender, grade, average browsing hours per session, average in the first semester)?

To answer the fifth question the means and standard deviations were calculated for the Internet addiction level among high school students at Irbid public schools according to the variables (study branch, gender, grade, average browsing hours per session, average in the first semester), as shown in table (10) below:

Table (10) arithmetic means \& standard deviations for the Internet addiction level among high school students at Irbid Public Schools according to the variables (study branch, gender, grade, average browsing hours per session, average in the first semester)

\begin{tabular}{lllll}
\hline \multicolumn{1}{c}{ Variables } & \multicolumn{1}{c}{ Levels/Classes } & \multicolumn{1}{c}{ Means } & STDEV & Number \\
\hline \multirow{3}{*}{ Study Branch } & Scientific & 3.52 & 0.95 & 111 \\
\cline { 2 - 5 } & Literary & 3.37 & 0.98 & 125 \\
\cline { 2 - 5 } Gender & Other Branches & 3.46 & 0.96 & 101 \\
& Male & 4.12 & 0.62 & 179 \\
\cline { 2 - 5 } Grade & Female & 2.68 & 0.71 & 158 \\
\hline \multirow{2}{*}{$\begin{array}{l}\text { Average browsing hours } \\
\text { per session }\end{array}$} & First High school & 3.40 & 0.99 & 188 \\
\cline { 2 - 5 } & Second High school & 3.50 & 0.96 & 149 \\
\hline \multirow{3}{*}{ First Term Average } & Between (2-5) hrs & 3.22 & 0.90 & 112 \\
\cline { 2 - 5 } & Greater than 5 hrs & 3.52 & 0.90 & 130 \\
\cline { 2 - 5 } & Between (80-100) & 3.61 & 1.11 & 95 \\
\cline { 2 - 5 } & Between (60-79) & 3.12 & 0.88 & 143 \\
\cline { 2 - 5 } & Less than 60 & 4.16 & 0.50 & 102 \\
\hline
\end{tabular}

Table (10) shows an apparent variation in the arithmetic means and standard deviations of Internet addiction level among high school students at Irbid public schools due to the difference in variables' categories: (study branch, gender, grade, average browsing hours per session, average in the first semester) and to calculate and show the statistical significant differences between the arithmetic means the Five Likert variation scale was used, as shown in table (11) below:

Table (11) Five Likert variation analysis for the impact of study branch, gender, grade, average browsing hours per session, first term average on the Internet addiction level among high school students at Irbid Public Schools

\begin{tabular}{llllll}
\hline Source of Variation & Sum of Squares & DF & Mean Square & F & Sig \\
\hline Study Branch & 1.356. & 2 & 0.678 & 1.739 & 0.177 \\
\hline Gender & 174.693 & 1 & 174.693 & 448.081 & 0.000 \\
\hline Grade/ Class & 0.353 & 1 & 0.353 & 0.905 & 0.342 \\
\hline Average browsing hours per session & 3.891 & 2 & 1.946 & 4.991 & 0.007 \\
\hline First Term Average & 12.181 & 2 & 6.090 & 15.622 & 0.000 \\
\hline Error & 127.877 & 328 & 0.390 & & \\
\hline Total & 320.351 & 336 & & & \\
\hline
\end{tabular}

It shows from table (11) the following points:

- The absence of statistically significant differences at level $(\alpha=0.05)$ due to the impact of study branch where the value of $\mathrm{F}$ amounted to (1.739) at a statistical significance of (0.177).

- This may be attributed to the fact that Internet addiction isn't limited to students in a particular branch without other branches or some of them therefore Internet addiction can occur to any student at any high school branch where the type of high school branch doesn't prevent the student from being addicted to the Internet and from this standpoint the effects of arithmetic means were similar among all study branches.

- The existence of statistically significant differences at level $(\alpha=0.05)$ due to the impact of gender where the value of $\mathrm{F}$ amounted to (448.081) at a statistical significance of $(0.000)$ and the differences came in favor of male.

- This may be attributed to the nature of life in Jordanian society where males are more liberal than 
females as they are less connected with family members and the house environment. The duties that are required from females aren't required from males like the daily household chores and family control over males are less than female who have constant contact with parents which make them busy and at regular contact with the whole family. This may keep females from taking the sufficient amount of time to use the Internet or browse it freely as males who spend long hours alone, have plenty of time, and don't have many duties or tasks that make them busy. Therefore, males find great and wide opportunities to surf and browse the internet freely.

- The absence of statistically significant differences at level $(\alpha=0.05)$ due to the impact of grade where the value of $\mathrm{F}$ amounted to (0.905) at a statistical significance of $(0.342)$.

- This may be attributed to the fact that first and second grade high school students are from the age groups that aren't separated by large age differences where the difference between these two grades is only one year and may make the circumstances similar among the students of both grades in Internet use and the time spent by the two parties may be similar which make the difference between the two grades confine and become almost identical. Therefore, Internet addiction may occur among any member of the two groups if the circumstances allow it to happen and the vulnerability of both parties to the Internet will be similar.

- The existence of statistically significant differences at level $(\alpha=0.05)$ due to the impact of average browsing hours per session where the value of $F$ amounted to (4.991) at a statistical significance of $(0.007)$ and in order to reveal in favor of any categories were those differences the Dimensional Post Hoc Multiple Comparisons were implemented by using the Scheffe Method, as shown in table (12) below:

Table (12) Multiple Comparisons by the Scheffe Method for the impact of average browsing hours per session on the Internet addiction level among high school students at Irbid Public Schools

\begin{tabular}{lllll}
\hline & Mean & Less than 2 hrs & Between (2-5) hrs & Greater than 5 hrs \\
\hline Less than 2 hrs & 3.22 & & & \\
\hline Between (2-5) hrs & 3.52 & ${ }^{*} 0.301$ & & \\
\hline Greater than 5 hrs & 3.61 & ${ }^{*} 0.393$ & 0.092 & \\
\hline
\end{tabular}

* Significant at level $(\alpha=0.05)$

It shows from table (12) statistically significant differences at level $(=0.05)$ between (less than $2 \mathrm{hrs})$ from one side and each of (2-5 hrs) and (greater than $5 \mathrm{hrs}$ ) on the other side, and the differences came in favor of both (2-5 hrs) and (greater than $5 \mathrm{hrs}$ ).

This may be attributed to the fact that students who may show symptoms of Internet addiction, the time period they use the Internet will be one of the indicators on Internet addiction where Internet addicts won't stay only for a short time in surfing the Internet since it doesn't satisfy all their needs and desires but they tend to spend the longest time period in Internet surfing to satisfy their needs and desires that may increase and develop day by day. It's noticeable in the daily life and from monitoring these groups of students that they are fond of using the Internet especially through their mobile phones where they now have a lot of contacts and activities that they practice daily and intensively through the Internet. Therefore, students and these age groups of individuals may have various goals they try to accomplish through their continuous connection via the Internet regardless of the nature of those goals, whether it's useful or useless.

From this standpoint, the long periods of time these students spend surfing the Internet may cause symptoms and problems which result from constantly sitting behind the electronic screens that students use for this purpose, such as exhaustion, constant nervousness, distance from parents and friends, and psychological and social isolation. Therefore, long time period had a statistical effect on the occurrence of Internet addiction.

The existence of statistically significant differences at level $(\alpha=0.05)$ due to the impact of average in the first semester where the value of F amounted to (15.622) at a statistical significance of (0.000) and in order to reveal in favor of any categories were those differences the Dimensional Post Hoc Multiple Comparisons were implemented by using the Scheffe Method, as shown in table (13) below:

Table (13) Multiple Comparisons by the Scheffe Method for the impact of first term average on the Internet addiction level among high school students at Irbid Public Schools

\begin{tabular}{lllll}
\hline & Mean & Between (80-100) & Between (60-79) & Less than 60 \\
\hline Between (80-100) & 3.16 & & & \\
\hline Between (60-79) & 3.12 & 0.045 & $* 1.045$ & \\
\hline Less than 60 & 4.16 & $* 1.000$ & & \\
\hline
\end{tabular}

\section{* Significant at level $(\alpha=0.05)$}

It shows from table (13) statistically significant differences at level $(=0.05)$ between (less than 60$)$ from one side and each of (60-79) and (80-100) on the other side, and the differences came in favor of (less than 60). 
This may be attributed to the fact that Internet addiction may be associated with spending long period of time in surfing or browsing the Internet in order for individual to reach the level of satisfaction in surfing the Internet despite the fact that it will be hard for Internet addict to reach an acceptable level of satisfaction which make students who have the tendency to internet addiction to spend the long hours being busy with the Internet and away from their studies. This may make their grades drop as a result of not following their studies most of the time and may even avoid many of the daily duties in their life and school assignments in order to surf the internet which make those students unlike their peers who may surf the Internet fairly according to their actual needs and balance between their studies and any other influencer that may affect their daily life and studies like Internet, relationships with friends, and even family relationships which make them maintain good grades in the different subjects at school, unlike internet addicts who can't balance between their studies and the compulsive Internet browsing.

Sixth Question: What is the relationship between Internet addiction level among high school students at Irbid public schools and their psychosocial adaptation problems?

To answer the sixth question, Pearson Correlation Coefficient was used to test the relationship between Internet addiction level among high school students at Irbid Public Schools and their psychosocial adaptation problems, as shown in table (14) below:

Table (14) Pearson Correlation Coefficient for the relationship between Internet addiction level among high school students at Irbid Public Schools and their psychosocial adaptation problems

\begin{tabular}{lllll}
\hline \multirow{3}{*}{$\begin{array}{l}\text { Internet } \\
\text { Addiction }\end{array}$} & $\begin{array}{l}\text { Correlation } \\
\text { Coefficient } \mathrm{R}\end{array}$ & $0.778(* *)$ & $\begin{array}{l}\text { Social Adaptation } \\
\text { Pdaptation Problems }\end{array}$ & $\begin{array}{l}\text { Psychosocial } \\
\text { Adaptation Problems }\end{array}$ \\
\cline { 2 - 5 } & Sig & 0.000 & $0.815(* *)$ & $0.838\left(^{* *}\right)$ \\
\cline { 2 - 5 } & Number & 337 & 0.000 & 0.000 \\
\hline
\end{tabular}

* Significant at level $(\alpha=0.05)$

** Significant at level $(\alpha=0.01)$

It shows from table (14) a statistically positive significant relationship between Internet addiction level among high school students at Irbid public schools and their psychosocial adaptation problems.

This may be attributed to the fact that Internet addiction is one of the problems that can make a lot of changes in the nature of individuals' life with the fact that high school students are from the youthful age group (16-18) years and these group have different characteristics from the previous stages where individuals at these stages become closer to puberty and have the tendency to be isolated. On the psychological level there are substantial differences related to these age group, such as the attempt to be independent in making decisions and selecting friends and partners. Members of this group are more influence by the social factors and more incline to receive the behaviors from individuals other than parents, such as actors, players, and singers. Many of them try to escape from their reality into a fantasy reality that they imagine for themselves and there is no doubt that Internet is the one capable of making this world for them therefore many of them will surf the Internet voraciously to search for this imaginary world which may satisfy the wishes and thoughts of many of them. This leads to the waste of long time and face the various problems, such as psychological, moral, religious, or social in addition to the physical problems, such as money, cybercrimes, and the conflicts that may turn into a reality where through it real crimes will happen on the ground.

From this standpoint Internet addiction may cause a lot of psychosocial adaptation problems among the students who tend to be addicted to the Internet in general due to a strong connection with their own world away from reality and from their parents, and sometimes from their friends. Students learn the different behaviors that they see on the Internet through their friends and social networks as their real life become unsatisfactory and don't meet their needs and desires and this make their psychological and social problems become visible and noticed by others.

\section{Recommendation}

In light of the study results the researcher recommends the following:

- The officials, parents, and society must have bigger interest in the topic of Internet addiction especially among high school students by monitoring the behaviors of students in relation to their use of the Internet and the hours student spend using the Internet in any way possible whether at home or at school.

- Develop correctional programs and treatment plans to reduce Internet addiction among high school students by finding different alternatives for high school students to get out of the Internet addiction dilemma.

- Continuous communication between parents, school, and students to understand their problems and make an attempt to resolve it without turning into the Internet. 
- Activate the role of school and community advisers, counselors, and principals to raise awareness about the threats and risks of Internet addiction and follow up the different cases of students to reduce this phenomenon.

- Conduct further studies on other study levels and at other regions to follow the developments in the Internet addiction field and the psychological and social effects and problems that can create among students and link the studies with topics other than psychological and social problems.

- Incorporate some lessons in the basic educational phase in some course materials and conduct lectures and sessions to raise awareness of the various risks and their effects, like Internet addiction.

\section{References}

Abdul R. \& Rafat M. (2013), "The Role of Social Media in Shaping the Political Awareness", Unpublished Master Thesis, Petra University, Jordan

Abu S. \& Abdullah Y. (2009), "Psycho-Social Adaptation and its Relationship with the Internal-External Control Center for the Disabled at Gaza Strip", Unpublished Master Thesis, Islamic University, Gaza.

Al-Hajj, F. M. (2017), "The Effectiveness of Self-Specific Treatment Program in reducing the Severity of Psychological Illness Symptoms of Internet Addiction among Students of the Faculty of Education at AlQassim University", Educational Sciences, 4 (2), p. 433-487

Al-Hattab, L. H. (2015), "Psychosocial Adaptation among a Sample of Students with Integrated and NonIntegrated Visual Disabilities in Jordan", Jordanian Journal for Educational Sciences, Volume (11), Issue 3, p. 303-317

Al-Khawaja, A. M. S. (2014), "Internet Addiction and its Relationship with the Psychological Adaptation among Students of Sultan Qaboos University", Al Quds Open University for Journal of Educational and Psychological Studies, 2(8), p. 79-102

Al-Naimi, Y. S. J. (2017), "Internet addiction and its relationship with the psychosocial Adaptation among Students of the Faculty of Physical Education \& Sports Sciences at Diyala University", Journal of Sports Sciences, Volume 9, Issue (29), p. 42-56

Al-Osaimi, S. A. M. (2010), "Internet Addiction and its Relationship with the Psychosocial Adaptation among High School Students in Riyadh", Unpublished Master Thesis, Prince Nayif Arab University for Security Sciences, Saudi Arabia

Al-Saed R. O. (2017), "Psychosocial Adaptation and its Relationship with Self-Esteem among Prison Inmates at Khartoum State", Unpublished Doctoral Thesis, Rabat National University, Sudan

Al-Tamimi, K. Bin H.; Marzouk, M. bin A. \& Al-Eidi , A. Bin G. (2007), "The Addiction to social networking among students of King Abdul-Aziz University and its relationship with their mental health", Journal of Educational and Psychological Studies (Journal of the Faculty of Education in Zagzig, 2(97), p. 1-50

American Psychiatric Association (2014), New Research Press Briefing: Internet Addiction: Review of Neuroimaging Studies, Retrieved on 13/9/2018 from:

https:/www.psychiatry.org/newsroom/news-releases/Internet-addiction-review-of-neuroimaging-studies

Arpaci, I; Kesici, Ş \& Baloğlu, M. (2018), "Individualism and Internet Addiction: The Mediating Role of Psychological Needs", Internet Research, Vol. 28 (2), pp.293-314, https://doi.org/10.1108/IntR-11-20160353

Azher, M. Khan, R. B. Salim, M. Bilal, M. Hussain, A. Haseeb, M. (2014), "The Relationship between Internet Addiction and Anxiety among students of University of Sargodha", International Journal of Humanities and Social Science, Vol. 4(1), p. 288-293

Castiglione, James (2008), "Internet abuse and possible addiction among undergraduates: A developing concern for library and university administrators", Emerald Insight (Library Review), Vol. 57(5), p. 358-371

Czincz, J. \& Hechanova, R. (2009), "Internet Addiction: Debating the Diagnosis", Journal of Technology in Human Services, Vol. 27, p. 257-272

Demir, Y. \& Kutlu, M. (2018), "Relationships among Internet Addiction, Academic Motivation, Academic Procrastination, and School Attachment in Adolescents", International Online Journal of Educational Sciences, Vol. 10 (5), p. 315-332

Herona, Dawn \& Shapira, Nathan A. (2003), "Time to log off New diagnostic criteria for problematic Internet use The MOUSE screening instrument helps identify five behaviors that spell too many hours online" Current, VOL. 2, NO. 4

İbili, Emin (2017), "Internet Addiction Levels and Problem Solving Skills in the Teaching Profession: An Investigation", Acta Didactica Napocensia, Vol. 10(4), p. 93-17

İlhan, A.; Çelik, H.; Gemcioğlu, M. and Çiftaslan, M. (2016), "Examination of the Relationship between Internet Attitudes and Internet Addictions of 13-18-Year-Old Students: The Case of Kahramanmaraş", Turkish Online Journal of Educational Technology, Vol. 15(2), p. 73-77

Iyitoğlu, Orhan; Çeliköz, Nadir (2017), "Exploring the Impact of Internet Addiction on Academic 
Achieve1ment", European Journal of Education Studies, Vol. 3(5), p. 38-59

Karimzadeh, N. (2015), "Investigating the Relationship between Internet Addiction and Strengthening Students' Social Skills", Educational Research and Reviews, Vol. 10(15), p. 2146-2152

Kenneth, M. \& Woog, D. (2004), "A Survey of Mental Health Professionals Clinical Exposure to Problematic Computer Use", Web page, Retrieved on 7 March from: http://www.pcmoderator.com/research.pdf

Kesici, Ahmet \& Tunç, Nazenin Fidan (2018), "The Development of the Digital Addiction Scale for the University Students: Reliability and Validity Study", Universal Journal of Educational Research, Vol. 6(1), p. 91-98

Ko, CH. Liu, TL. Wang, PW. Chen, CS. Yen, CF. Yen, JY. (2014), "The exacerbation of depression, hostility, and social anxiety in the course of Internet addiction among adolescents: A prospective study", Science Direct, Comprehensive Psychiatry, Vol. 55, p. 1377-1384

Li, Yajun; Zhang, Xinghui; Lu, Furong; Zhang, Qin; Wang, Yun (2014), "Internet Addiction among Elementary and Middle School Students in China: A Nationally Representative Sample Study", Cyberpsychology, Behavior and Social Networking, Vol. 17(2), p. 111-116

Matar, Abdel Fattah, Ghanayem, Adel \& Abdul Hadi, Mohammed (2009), "Internet Addiction and its relationship with both Depression and Social Support of University Students", Studies in the Psychology of Disabled Persons, Alexandria, Dar Al-Wafaa for Publishing and Distribution

Müller, Kai W.; Glaesmer, Heide; Brahler, Elmar; Woelfling; Klaus \& Beutel; Manfred E. (2014), "Prevalence of Internet addiction in the general population: results from a German population-based survey", Behavior \& Information Technology, Vol. 33(7), p. 757-766

Musa, Magidah (2010), "The Concept of Social Self and its Relationship with the Psycho-Social Adaptation among the Blind Person", Damascus University Magazine, Volume (26), p. 409-451

Sofian, Nabil Saleh (2004), "The Acronym in Personality and Psychological Guidance, your Guide to Discover your Personality and Other Personality", First Edition, Cairo, Dar Etrac for Publishing and Distribution

Tarawneh, Nayif Salem \& Al-Fanikh, Lamia Suleiman (2012), "The Use of Internet and its relationship with the Academic Achievement, Social Adaptation, Depression, and Communication Skills among students of AlQassim University", The Journal of Islamic University for Educational and Psychological Studies, Volume (20), Issue (1), p. 283-331

Taş, İbrahim (2017), "Relationship between Internet Addiction, Gaming Addiction and School Engagement among Adolescents", Universal Journal of Educational Research, Vol. 5(12), p. 2304-2311

Varma, P.; Cheaskul, U.; Poonpol, P. (2018), "The Influence of Parenting Styles on Academic Adjustment and Psychological Well-Being among Thai University Students Mediated by Internet Addiction and SelfRegulation: A Path Model", Journal for Leadership and Instruction, fall 2018, p. 13-24

Abdullah Al-Shoqran (M'98) he was Born in Al-Ramtha in 1973, This author became a Member (M) of AlBalqa' Applied University in 1998 and still up to date. He holds a Ph.D. in Educational Administration from Yarmouk University in Jordan in 2012. His research interests are: Educational information technology, educational administration, educational organization and educational computer. 